\title{
Serum selenium levels in pulmonary tuberculosis levels with and without HIVIAIDS
}

\author{
K Ramakrishnan*1,4, S Praveen Sharma ${ }^{2}$, R Shenbagarathai ${ }^{3}$, K Kavitha ${ }^{5}$ and \\ P Thirumalaikolundusubramanian ${ }^{5}$
}

\begin{abstract}
Address: 'Tuberculosis Research Centre, Government Rajaji hospital, Madurai-625020, Madras Medical College, Chennai-600003, India, ${ }^{2}$ Department of Microbiology, Madurai Medical College, Madras Medical College, Chennai-600003, India, ${ }^{3}$ Department of Biotechnology, Lady Doak College, Madras Medical College, Chennai-600003, India, 47th Day School, Madurai-625002, Madras Medical College, Chennai-600003, India and ${ }^{5}$ Institute of Internal Medicine, Madras Medical College, Chennai-600003, India

* Corresponding author
\end{abstract}

from Frontiers of Retrovirology: Complex retroviruses, retroelements and their hosts

Montpellier, France. 21-23 September 2009

Published: 24 September 2009

Retrovirology 2009, 6(Suppl 2):P76 doi:10.1186/1742-4690-6-S2-P76

This abstract is available from: http://www.retrovirology.com/content/6/S2/P76

(c) 2009 Ramakrishnan et al; licensee BioMed Central Ltd.

\section{Background}

Selenium is an essential trace element and it plays an important role in immunity.

\section{Aim}

The present study is to find out the selenium levels in pulmonary tuberculosis (PTB) patients with and without HIV infection and compare with healthy control and correlate with Body Mass Index (BMI).

\section{Materials and methods}

A cross sectional study was carried out to estimate serum Selenium levels in newly detected, untreated active PTB patients with $(\mathrm{N}=30)$ and without $\operatorname{HIV}(\mathrm{N}=33)$, attending to Thoracic medicine department of Government Rajaji Hospital, Madurai who satisfied rigid selection criteria. Thirty healthy individuals (family members of the patients) were kept as control. Standard method were adopted to collect early morning fasting blood samples for selenium estimation by AAS (atomic absorption spectrometry) in the Department of Biotechnology, Lady Doak College, Madurai. The study was approved by the Institutional Ethical Committee, and informed consent was obtained from participants.

\section{Results}

The range, mean and median of serum Selenium levels in PTB patients with and with HIV coinfection were 16 to
$101.7,66.6$, and $69 \mu \mathrm{g} / \mathrm{dl}$; and 29 to $109,71.9$, and $73 \mu \mathrm{g} /$ $\mathrm{dl}$ respectively. The same in control were 101 to129, 113.1 , and $111.6 \mu \mathrm{g} / \mathrm{dl}$ respectively. The mean (S.D) BMI status of HIV positive PTB, HIV negative PTB and control were $18(0.4), 18.5(0.6)$ and 19.9 (0.6) respectively. The differences among the group were statistically significant.

\section{Conclusion}

The present findings suggest that Selenium status of patients with active pulmonary TB is low when compared with healthy control. Low concentration of serum Selenium as well as wasting was noticed significantly in PTB patients with HIV infection than non HIV subjects. Hence, these cases require nutritional supplements containing selenium. 